\title{
A survey of newly appointed consultants' attitudes towards research fraud
}

D Geggie Arrowe Park Hospital, Arrowe Road, Upton, Wirral, Merseyside

\begin{abstract}
Objective-To determine the prevalence of, and attitudes towards, observed and personal research misconduct among newly appointed medical consultants.

Design-Questionnaire study.

Setting-Mersey region, United Kingdom. Participants-Medical consultants appointed between Fan 1995 and Fan 2000 in seven different hospital trusts (from lists provided by each hospital's personnel department).

Main outcome measures-Reported observed misconduct, reported past personal misconduct and reported possible future misconduct.

Results-One hundred and ninety-four replies were received (a response rate of 63.6\%); 55.7\% of respondents had observed some form of research misconduct; $5.7 \%$ of respondents admitted to past personal misconduct; $18 \%$ of respondents were either willing to commit or unsure about possible future research misconduct. Only $17 \%$ of the respondents reported having received any training in research ethics. Anaesthetists reported a lower incidence of observed research misconduct (33.3\%) than the rest of the respondents $(61.5 \%)(p<0.05)$.

Conclusion-There is a higher prevalence of observed and possible future misconduct among newly appointed consultants in the UK than in the comparable study of biomedical trainees in California. Although there is a need for more extensive studies, this survey suggests that there is a real and potential problem of research misconduct in the UK.

(Fournal of Medical Ethics 2001;27:344-346)
\end{abstract}

Keywords: Research fraud; research misconduct; research ethics; scientific fraud; scientific misconduct; fraud

\section{Introduction}

There seems little doubt that research fraud does occur. Beyond that, however, very little is known about it. A medline search revealed only two papers (both questionnaires) which addressed the prevalence of research fraud. ${ }^{12}$ One of these papers was American and one was Norwegian and both papers directed their questionnaires at different target populations. The American study was directed at biomedical trainees and the Norwegian study was directed at academic medical researchers. The
Norwegian study reported that $18 \%$ of respondents agreed fully or in part that they had been exposed to scientific misconduct whilst the American study reported that $15.1 \%$ of their respondents admitted personal instances of misconduct. The author wondered if these papers' conclusions would be valid in a different country among recently appointed medical consultants nearly a decade later.

\section{Method}

A modified version of the original questionnaire used by Kalichman and Friedman was sent to all newly appointed (not necessarily the same as newly qualified) medical consultants (appointed between Jan 1995 and Jan 2000) working for seven separate hospital trusts in the Mersey region. ${ }^{1}$ The breakdown of the different hospitals involved was four district general hospitals, two university teaching hospitals and one specialist paediatric hospital. A stamped addressed envelope was enclosed with each questionnaire for the replies. A covering letter was sent with each questionnaire emphasising that each individual reply would be kept anonymous and that only generalised conclusions would be drawn from the questionnaire. In all 305 questionnaires were sent out between February and April 2000.

\section{Results}

In total 194 replies were received (a response rate of $63.6 \%$ ) (see table 1).

One hundred and eight $(55.7 \%)$ of the respondents reported that they had observed some form of research misconduct (ie answered yes on question 1,2 or 3 ) ( see table 2 ).

The most frequently reported form of observed research misconduct was that of inappropriate authorship (ie yes to question 1) reported by 72 ( $37.1 \%)$ of the respondents. Fifty-eight $(29.9 \%)$ reported that their names had been omitted from papers to which they had made a substantial contribution and $21(10.8 \%)$ reported having firsthand knowledge of the intentional altering or fabrication of data for the purposes of publication.

Eleven $(5.7 \%)$ of the respondents admitted to past personal misconduct (ie answered yes to questions $4 \mathrm{a}, 4 \mathrm{~b}, 4 \mathrm{c}$, or $4 \mathrm{~d})$. 


\begin{tabular}{|c|c|c|c|c|}
\hline & Yes & No & Unsure & $\begin{array}{l}\text { NA } \\
\text { (no answer) }\end{array}$ \\
\hline $\begin{array}{l}\text { 1. Have you been an author on a paper for which any of the authors had not } \\
\text { made a sufficient contribution to warrant credit for the work? }\end{array}$ & 72 & 120 & & 2 \\
\hline $\begin{array}{l}\text { 2. Has your name ever been omitted from a paper for which you had made a } \\
\text { substantial contribution? }\end{array}$ & 58 & 133 & & 3 \\
\hline $\begin{array}{l}\text { 3. Do you have firsthand knowledge of scientists or doctors intentionally altering } \\
\text { or fabricating data for the purpose of publication? }\end{array}$ & 21 & 172 & & 1 \\
\hline \multicolumn{5}{|l|}{ 4. Since entering medical school have you: } \\
\hline A) cheated to improve a test grade? & 4 & 190 & & 0 \\
\hline B) modified research or experimental results to improve the outcome? & 4 & 189 & & 1 \\
\hline C) reported research or experimental results which you knew to be untrue? & 2 & 192 & & 0 \\
\hline D) plagiarised the work of someone else? & 2 & 192 & & 0 \\
\hline \multicolumn{5}{|l|}{ 5. If it would expedite publication of your work, would you be willing to: } \\
\hline A) fabricate data? & 0 & 191 & 3 & 0 \\
\hline B) omit data to fit your hypothesis? & 3 & 174 & 17 & 0 \\
\hline \multicolumn{5}{|l|}{ 6. If it would enhance a grant application, would you be willing to: } \\
\hline A) fabricate data? & 1 & 189 & 3 & 1 \\
\hline B) select or omit data to fit your hypothesis? & 8 & 167 & 19 & 2 \\
\hline 7. Do you feel it is necessary to publish papers in order to further your career? & 116 & 66 & 12 & 0 \\
\hline 8. Have you ever received any training in research ethics? & 33 & 161 & & 0 \\
\hline $\begin{array}{l}\text { 9. Do you think more resources and time should be spent investigating possible } \\
\text { research fraud? }\end{array}$ & 83 & 33 & 78 & 0 \\
\hline
\end{tabular}

Table 2 Derived variables

\begin{tabular}{lll}
\hline Observed misconduct & (Yes on question 1, 2, or 3) & $108(55.7 \%)$ \\
Past personal misconduct & (Yes on question 4a, 4b, 4c or 4d) & $11(5.7 \%)$ \\
Future possible misconduct & (Yes or maybe on question 5a, 5b, 6a or 6b) & $35(18.0 \%)$ \\
\hline
\end{tabular}

Four $(2.1 \%)$ admitted cheating on a test and the same percentage admitted modifying research or experimental results to improve the outcome. Two $(1.0 \%)$ of the respondents admitted that they had reported untrue research or experimental results and two of the respondents admitted plagiarising the work of other people.

One hundred and fifty-nine $(82 \%)$ of the respondents were not willing to consider future

Table 3 Breakdown of respondents by specialty

\begin{tabular}{lc}
\hline Accident and emergency & $5(2.6 \%)$ \\
Anaesthetics & $32(16.5 \%)$ \\
Cardiology & $2(1 \%)$ \\
Geriatric medicine & $3(1.5 \%)$ \\
Haematology & $5(2.6 \%)$ \\
Histopathology & $9(4.6 \%)$ \\
General medicine & $15(7.7 \%)$ \\
Neurosurgery & $1(0.5 \%)$ \\
Obstetrics/gynaecology & $7(3.6 \%)$ \\
Ophthalmology & $8(4.1 \%)$ \\
Orthodontics & $8(4.1 \%)$ \\
Orthopaedic surgery & $9(4.6 \%)$ \\
Otolaryngology & $4(2.1 \%)$ \\
Paediatrics & $12(6.2 \%)$ \\
Psychiatry & $6(3.1 \%)$ \\
Radiology & $15(7.7 \%)$ \\
Surgery & $16(8.2 \%)$ \\
Urology & $1(0.5 \%)$ \\
Other specialties or not specified & $36(18.6 \%)$ \\
\hline
\end{tabular}

Table 4 Breakdown of responses from anaesthetists (no of respondents $=36$ )

\begin{tabular}{lc}
\hline Observed misconduct & $12(33.3 \%)$ \\
Past personal misconduct & $1(2.8 \%)$ \\
Future possible misconduct & $5(13.9 \%)$ \\
\hline
\end{tabular}

possible research misconduct (no to question $5 \mathrm{a}$, $5 \mathrm{~b}, 6 \mathrm{a}$ and $6 \mathrm{~b}$ ) which leaves the remaining 35 being either willing to commit (eight $[4.1 \%]$ ) or being unsure about (27 [13.9\%]) possible future research misconduct.

The majority of respondents (116 [59.8\%]) felt it necessary to publish papers in order to further their careers and a minority of respondents (17\%) reported having received any training in research ethics.

Of the 194 respondents, $83(42.8 \%)$ felt that more time and resources should be spent investigating possible research fraud whilst a similar percentage $(40.2 \%)$ was unsure.

Only $33(17 \%)$ answered no to this question.

Of those who replied, $32(16.5 \%)$ stated their specialty as being anaesthetics; $16(8.2 \%)$ surgery; $15(7.7 \%)$ general medicine; $15(7.7 \%)$ radiology; $12(6.2 \%)$ paediatrics, and $9(4.6 \%)$ orthopaedic surgery. (See table 3). Anaesthetists reported a lower incidence of observed research misconduct $(33.3 \%)$ than the rest of the respondents $(61.5 \%)$ and this reached statistical significance on a $\chi$-squared test $(p<0.05)$ (see table 4$)$.

Surgeons reported a higher incidence of observed research misconduct $(68.7 \%)$ than the rest of the respondents $(55.1 \%)$ but this difference is not statistically significant.

\section{Discussion}

The true prevalence of research misconduct appears unknown and most references to it are speculative. In 1988 Lock reported that over half of the academics he had questioned knew of instances 
of misconduct. ${ }^{3}$ This was, however, a small non-systematic survey. Research misconduct has probably been around for many years and doubts have been cast upon the integrity of such seminal work as Mendel's original work on the hybridisation of plants and Newton's work on sound, gravity and precession. ${ }^{45}$ Research fraud can take many forms- ranging from subtle biased patient selection and fraudulent statistical manipulation to the complete fabrication of results and evidence. Medical careers are, by their very nature, competitive and a majority of respondents $(59.8 \%)$ reported a pressure to publish in order to further their careers: $55.7 \%$ of respondents had observed some form of misconduct. Nearly one in five $(18 \%)$ of the respondents were, at best, unsure about possible future research misconduct. The consultants targeted by this questionnaire are doctors who, by virtue of the nature of their jobs, will probably be taking a lead in the future clinical research in their particular fields and this, therefore, represents a sizable potential problem. There are no easy solutions to the problem of research fraud but there was evidence of substantial support for more resources to be spent on investigating potential research fraud. Only $17 \%$ of the respondents reported having received any training in research ethics. If we, as a profession, are to tackle the problem of scientific fraud, we must surely increase this percentage as well as reducing the pressures on (and rewards of) researchers publishing.

In conclusion, this study shows a higher percentage of observed misconduct $(55.7 \% \mathrm{v} 35.5 \%)$ among newly appointed consultants than the comparative study of biomedical research trainees by Kalichman and Friedman. ${ }^{1}$ There was also a higher percentage of possible future misconduct $(18.0 \% \mathrm{v}$ $14.8 \%$ ) among newly appointed consultants.

These differences may reflect a higher prevalence of actual research misconduct or may, to some degree, reflect differences between the different study populations-for example, a lower threshold for the perception of research misconduct. Different groups of researchers have been shown to have different perceptions of which practices constitute research misconduct. ${ }^{6}$

I acknowledge that this study had a relatively small sample size and that further, larger studies would be required to shed more light onto what is an area fraught with difficulties for investigators. In particular, it would be interesting to know if the Mersey region is typical of the country as a whole; if there is a difference in the responses from consultants in academic posts from those in non academic posts; if the non-respondents in the survey were more or less likely to have experienced research fraud, and how the non-respondents differed in their background from the respondents. Newly appointed consultants differ in many characteristics from other doctors and it would be unwise automatically to extrapolate these results to the entire profession. I do, however, believe that this survey indicates that there is a real and potential future problem of research fraud in this country and that the magnitude of that problem is probably compatible with that experienced by other countries.

\section{Author's note}

Initial literature search strategy: Medline 1966 to 01/00 using OVID interface. Competing interests: none declared.

\section{Acknowledgements}

DG is the sole author. I thank my colleagues on the Mersey A\&E rotation and Dr Omnia Marzouk for their constructive advice and staff at Aintree Hospitals NHS Trust for secretarial support. The survey was funded by DG and Aintree Hospitals NHS Trust provided the stamped addressed envelopes.

D Geggie, Bsc, MBChB, FRCS, is Specialist Registrar in Accident and Emergency Medicine, Accident and Emergency Department, Arrowe Park Hospital, Arrowe Park Road, Upton, Wirral, Merseyside, CH49 5PE. Address for correspondence: as above and at: DAVID@GEGGIE.freeserve.co.uk

\section{References}

1 Kalichman M, Friedman P. A pilot study of biomedical trainees' perceptions concerning research ethics. Academic Medicine 1992;67:769-75.

2 Jacobsen G, Hals A. Medical investigators' views about ethics and fraud in medical research. Fournal of the Royal College Of Physicians Of London 1995;29:405-9.

3 Lock S. Research misconduct: a résumé of recent events. In: Lock S, Wells F, eds. Fraud and misconduct in medical research Lock S, Wells F, eds. Fraud and misconduct

4 Fisher R. Has Mendel's work been rediscovered? Annals Of Science 1936;1:115-24

5 Westfall R. Newton and the fudge factor. Science 1973;179: 751-8

6 Lynöe N, Jacobsson L, Lundgren E. Fraud, misconduct or normal science in medical research-an empirical study of demarcation. Fournal of Medical Ethics 1999;25:501-6. 